\title{
Subclinical Right Ventricular Dysfunction in Type 2 Diabetes Mellitus: An Echocardiographic Strain/Strain Rate Study
}

\author{
YASER R. MOHAMMED, M.D.*; WAEL R. HABLAS, M.D.**; ASHRAF M. ANWAR, M.D.*; \\ SAMY H. NOUH, M.D.*; ABD EL-HAMID I. ABD EL-HAMID, M.D.* and AYMAN T. EL-DESOUKY, M.Sc.*** \\ The Departments of Cardiology* and Clinical Pathology**, Faculties of Medicine, Al-Azhar University and \\ Department of Cardiology, Fowa Central Hospital, Kafr El-Sheikh***, Egypt
}

\begin{abstract}
Background: Type II Diabetes Mellitus (DM) was accompanied by subclinical impairment of Right Ventricular (RV) systolic dysfunction. Two-Dimensional (2D) Speckle Tracking Echocardiography (STE) allows a precise evaluation of myocardial function.
\end{abstract}

Aim of the Study: The aim of this study was to assess the RV systolic function in asymptomatic normotensive subjects with type II DM compared with control subjects, using strain/ strain rate qualification by $2 \mathrm{D}$ STE.

Subjects and Methods: Prospective study enrolled 100 subjects, they were classified into two groups: Group I included seventy subjects known to have type II DM (36 males and 34 females), mean age $41.37 \pm 4.72$ years, and group II included thirty healthy subjects ( 15 males and 15 females) with mean age $39.40 \pm 3.14$ years. All subjects had normal Left Ventricular (LV) Ejection Fraction (EF), calculated by conventional 2D Trans-Thoracic Echocardiography (TTE). Subjects who had diseases affecting LV and RV systolic functionwere excluded as hypertension, coronary artery disease, valvular diseases, arrhythmias, pulmonary diseases and pulmonary hypertension. All studied population were subjected to informed verbal consent, full history taking. General and cardiac examination were done. Resting standard 12-leads Electrocardiogram (ECG) has been recorded for analysis. HaemoglobinA1c (HbA1c \%) level was measured for group I. 2D TTE and 2D STE were done for all subjects. LV global longitudinal strain (LVGLS\%), RVGLS\%, RV segmental peak Longitudinal Systolic Strains (LSS\%) and RV segmental longitudinal systolic strain rates (LSSRs $1 / \mathrm{sec}$ ) were assessed by $2 \mathrm{D}$ STE. Data were collected and statistically analysed.

Results: Both groups showed no statistically significant difference regarding LV linear internal dimensions, EF, LV Mass Index (LVMI), RV inflow linear dimensions, Fractional Area Change (FAC) and Tricuspid Annular Post-Systolic Excursion (TAPSE). Mean values of LVGLS and RVGLS were significantly lower in group I than in group II, as mean values for GLS of LV \& RV were $(-19.93 \pm 1.48,-21.49 \pm 3.80$

Correspondence to: Dr. Yaser R. Mohammed, The Department of Cardiology, Faculty of Medicine, Al-Azhar University for group I respectively versus $-22.10 \pm 1.21,-26.40 \pm 2.86$ for group II respectively) with ( $p$-value $<0.001)$. The mean values of RV segmental LSS were lower in group I than in group II as mean values for basal septum, mid septum, apical septum, basal RV free wall and apical RV free wall were lower in group I. (-14.81 $\pm 4.02,-16.77 \pm 3.66,-18.20 \pm 3.42,-20.53 \pm$ $2.14,-24.41 \pm 5.72$ respectively) versus $(21.03 \pm 1.35,-22.73 \pm$ $2.00,-24.60 \pm 1.94,-30.37 \pm 3.11,-30.23 \pm 5.45$ respectively) for group II, ( $p$-value $<0.001)$, except for mid RV free wall which showed no statistically significant difference between both groups. No statistically significant difference between both groups was detected regarding mean values of RV segmental (LSSRs 1/sec), except for apical RV free wall which were significantly lower in group I $(1.18 \pm 0.54)$ than in group II $(1.48 \pm 0.54),(p$-value $=0.022)$. There was a reverse correlation between GLS of LV and RV with the duration of diabetes and the level of HbA1 C.

Conclusion: Subjects with type II DM were associated with subclinical LV \& RV systolic dysfunction compared with control subjects.

Key Words: Glycated haemoglobin - Global longitudinal strain - Speckle tracking echocardiography.

\section{Introduction}

DIABETES Mellitus (DM) may lead to diabetic cardiomyopathy which is defined as myocardial dysfunction independent of Coronary Artery Disease (CAD) and hypertension [1]

The development of diabetic cardiomyopathy is associated with structural and functional cardiomyocyte alterations, coronary microangiopathy and autonomic neuropathy, which at first lead to hypertrophy and subclinical cardiac dysfunction and then to symptomatic heart failure [2] .

The pathogenesis of diabetic cardiomyopathy is multifactorial: Hyperglycaemia, increased free fatty acids, hyperinsulinaemia, insulin resistance, and inflammatory cytokines change cellular meta- 
bolic pathways in cardiomyocytes and impair cardiac function [3].

However, the pathophysiological mechanisms of myocardial impairment in type I DM are slightly different as they are related mainly to hyperglycemia and free fatty acids, whereas in type II DM, the main harmful factor is hyperinsulinaemia and insulin resistance [4].

More studies have confirmed subclinical Left Ventricular (LV) and Right Ventricular (RV) systolic dysfunction in type II DM [5].

The RV function plays a significant role in the overall myocardial contractility. Nevertheless, most of the previous studies regarding diabetes-induced changes in myocardial dysfunction were dedicated to the $\mathrm{LV}$ at the cost of ignoring the role of the right heart chambers [6].

However, the assessment of RV function remains difficult, because of the complex geometry, non-uniform contraction and partly retro-sternal position of the RV as recently validated, strain/strain rate imaging, comprehensive approach providing extensive information about regional myocardial function, may be applicable to the RV [7] .

Speckle Tracking Echocardiograghy (STE) is a new echocardiographic technique that allows a precise evaluation of myocardial function. This method is accurate, reproducible, and angle independent, and it enables a complete assessment of regional and global function in three directions [8]

In contrast, Tissue Doppler Imaging (TDI) is angle dependent, prone to noises, less accurate, and able to assess limited region of tissue [8] .

\section{Subjects and Methods}

The study comprised seventy subjects known to have type II Diabetes Mellitus (DM), they were recruited from the Outpatient Endocrinology Clinic and Internal Medicine Department in Al-Hussein University Hospital and thirty subjects of apparently normal people with comparable age and sex as controls between July 2016 and June 2017.

The studied population included, were classified into two groups:

- Group I: Consisted of seventy subjects known to have type II DM (36 males and 34 females) mean age $41.37 \pm 4.72$ years.

- Group II: Consisted of thirty healthy subjects (15 males and 15 females) with mean age $39.40 \pm 3.14$ years.
Subjects were selected according to the following criteria:

- Inclusion criteria:

- Subjects known to have type II DM.

- Left Ventricular Ejection Fraction (LVEF) $\geq 53 \%$

by conventional echocardiography.

- Exclusion criteria:

- Type I DM.

- Hypertension.

- Obesity.

- Coronary artery disease.

- Poor quality echocardiographic imaging.

- Valvular and congenital heart disease.

- LVEF < $50 \%$.

- Endocrinal and systemic diseases other than diabetes.

- Renal failure.

- All other types of cardiomyopathy.

- Arrhythmias.

- Pulmonary disease and pulmonary hypertension.

- Sever tricuspid insufficiency.

- Systolic wall motion abnormalties of the LV at rest.

- Right ventricular wall motion abnormalities at rest.

\section{Methods:}

All studied population were subjected to the following:

1- Informed verbal consent.

2- Full history taking:

- Age.

- Sex.

- Onset of the diabetes.

- Duration of diabetes.

- Any associated illness.

3- General examination and cardiac examination: Including:

- Vital signs including Heart Rate (HR).

- Blood Pressure (BP): Systolic Blood Pressure (SBP) and Diastolic Blood Pressure (DBP) were measured. Blood pressure less than 140/90 is considered normotensive according to ESC guidelines [9].

4- Resting 12 lead electrocardiography: Resting standard 12-lead Electrocardiogram (ECG) has been recorded for analysis of rate, rhythm, bundle branch block, chamber enlargement and ECG criteria of ischemic heart disease. 
5- Haemoglobin A1c level for subjects of group I.

6- Echocardiographic examination: By 2D Transthoracicechocardiography (2D TTE) and 2D Speckle Tracking Echocardiography (2D STE).

Data were analyzed using Statistical Program for Social Science (SPSS) Version 20.0. Quantitative data were expressed as mean \pm Standard Deviation (SD). Qualitative data were expressed as frequency and percentage.

\section{Results}

Demographic data of the studied population:

There was no statistically significant difference between both groupsregarding age, sex and Body Surface Area (BSA), as shown in Table (1).

Table (1): Demographic data of the studied population.

\begin{tabular}{|c|c|c|c|c|}
\hline Demographic data & Group I & Group II & $t / \chi^{2} \#$ & $p$-value \\
\hline \multicolumn{5}{|l|}{ Age (years): } \\
\hline Mean \pm SD & $41.37 \pm 4.72$ & $39.40 \pm 3.14$ & 1.396 & 0.386 \\
\hline Range & $32-50$ & $33-45$ & & \\
\hline \multicolumn{5}{|l|}{ Sex: } \\
\hline Female & $34(48.6 \%)$ & $15(50 \%)$ & $0.017 \#$ & 0.896 \\
\hline Male & $36(51.4 \%)$ & $15(50 \%)$ & & \\
\hline \multicolumn{5}{|l|}{$B S A\left(m^{2}\right):$} \\
\hline Mean \pm SD & $1.78 \pm 0.17$ & $1.77 \pm 0.17$ & 0.016 & 0.898 \\
\hline Range & $1.52-1.96$ & $1.52-1.96$ & & \\
\hline
\end{tabular}

BSA: Body Surface Area.

\section{Clinical data of the studied population:}

There was no statistically significant difference between both groups regarding Systolic Blood Pressure (SBP), Diastolic Blood Pressure (DBP) and Heart Rate (HR), as shown in Table (2).

Table (2): Comparison between both groups regarding clinical data.

\begin{tabular}{lllll}
\hline Clinical data & \multicolumn{1}{c}{ Group I } & \multicolumn{1}{c}{ Group II } & $t$-test & $p$-value \\
\hline $\begin{array}{l}\text { SBP }(m m H g): \\
\text { Mean } \pm \text { SD }\end{array}$ & $\begin{array}{l}121.03 \pm 8.32 \\
104-137\end{array}$ & $\begin{array}{l}120.93 \pm 6.41 \\
109-132\end{array}$ & 0.003 & 0.956 \\
$\quad$ Range & & & & \\
DBP $(m m H g):$ & & & \\
$\quad$ Mean \pm SD & $71.47 \pm 5.88$ & $71.93 \pm 7.04$ & 0.115 & 0.735 \\
$\quad$ Range & $60-83$ & $59-84$ & & \\
HR $(b / m i n):$ & & & & \\
$\quad$ Mean \pm SD & $70.87 \pm 7.73$ & $67.70 \pm 6.60$ & 3.842 & 0.053 \\
$\quad$ Range & $55-85$ & $55-81$ & & \\
\hline
\end{tabular}

SBP : Systolic Blood Pressure.

DBP : Diastolic Blood Pressure.

HR : Heart Rate.

\section{Descriptive analysis of group I:}

The mean value of HBA1c\% level was $8.33 \pm$ 0.93 , with mean duration of diabetes $8.26 \pm 2.91$ years.

\section{Conventional 2D TTE of $L V$ :}

There was no statistically significant difference between both groups regarding Left Ventricular Internal Dimensions at both diastole and systole (LVIDd and LVIDs), Ejection Fraction (EF) and Left Ventricular Mass Index (LVMI), as shown in Table (3).

Table (3): Comparison between both groups regarding some LV parameters by conventional 2D TTE.

\begin{tabular}{|c|c|c|c|c|}
\hline $\begin{array}{l}\text { Conventional } \\
\text { 2D TTE of LV }\end{array}$ & Group I & Group II & $t$-test & $p$-value \\
\hline $\begin{array}{l}L V I D d(\mathrm{~cm}): \\
\quad \text { Mean } \pm \mathrm{SD} \\
\text { Range }\end{array}$ & $\begin{array}{l}4.43 \pm 0.49 \\
3.4-5.4\end{array}$ & $\begin{array}{l}4.43 \pm 0.48 \\
3.6-5.3\end{array}$ & 0.001 & 0.975 \\
\hline $\begin{array}{l}\text { LVIDs }(\mathrm{cm}): \\
\quad \text { Mean } \pm \text { SD } \\
\quad \text { Range }\end{array}$ & $\begin{array}{l}2.85 \pm 0.39 \\
2-3.6\end{array}$ & $\begin{array}{l}2.83 \pm 0.36 \\
2.1-3.5\end{array}$ & 0.060 & 0.807 \\
\hline $\begin{array}{l}E F \%: \\
\quad \text { Mean } \pm \text { SD } \\
\text { Range }\end{array}$ & $\begin{array}{l}64.20 \pm 3.23 \\
58-70\end{array}$ & $\begin{array}{l}64.47 \pm 3.16 \\
59-70\end{array}$ & 0.145 & 0.704 \\
\hline $\begin{array}{l}L V M I\left(g / m^{2}\right): \\
\quad \text { Mean } \pm \text { SD } \\
\quad \text { Range }\end{array}$ & $\begin{array}{l}71.20 \pm 12.38 \\
44-101\end{array}$ & $\begin{array}{l}70.53 \pm 12.26 \\
47-99\end{array}$ & 0.061 & 0.805 \\
\hline
\end{tabular}

LVIDd : Left Ventricular Internal Dimension at diastole.

LVIDs : Left Ventricular Internal Dimensionat systole.

EF : Ejection Fraction.

LVMI : Left Ventricular Mass Index.

\section{Conventional 2D TTE of $R V$ :}

There was no statistically significant difference between both groups regarding RV inflow dimensions (basal, mid-cavity and longitudinal diameters), Fractional Area Change (FAC) and Tricuspid Annular Post-Systolic Excursion (TAPSE), as shown in Table (4).

Table (4): Comparison between both groups regarding some RV parameters by conventional 2D TTE.

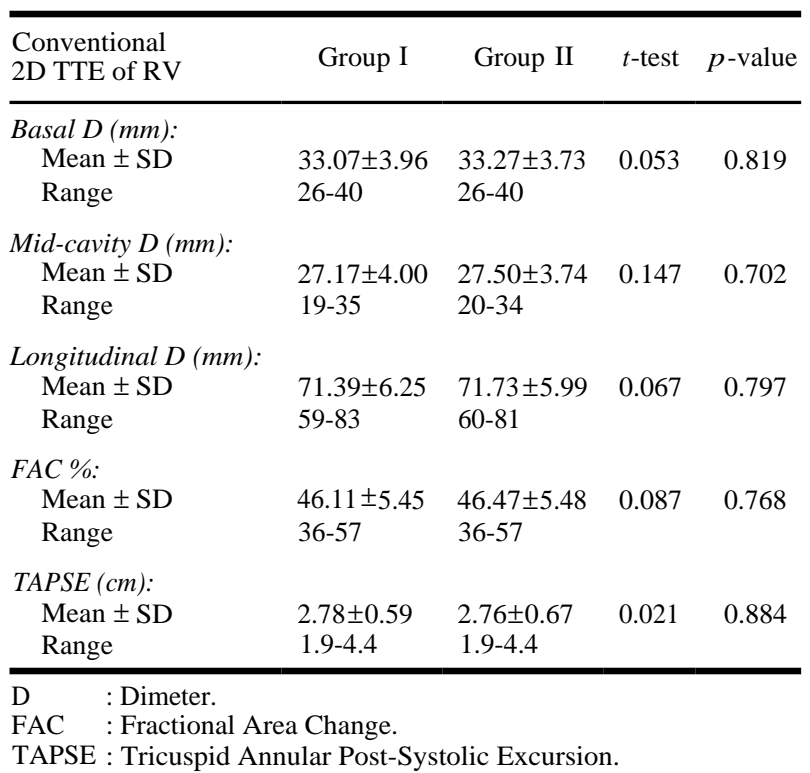




\section{D STE of the $L V$ :}

Mean values for LV Global Longitudinal Strain (LVGLS\%) showed highly statistically significant difference between both groups, it were lower in group I ( $-19.93 \pm 1.48$ for group I versus $-22.10 \pm$ 1.21 for group II), $p$-value $<0.001$, as shown in Fig. (1).

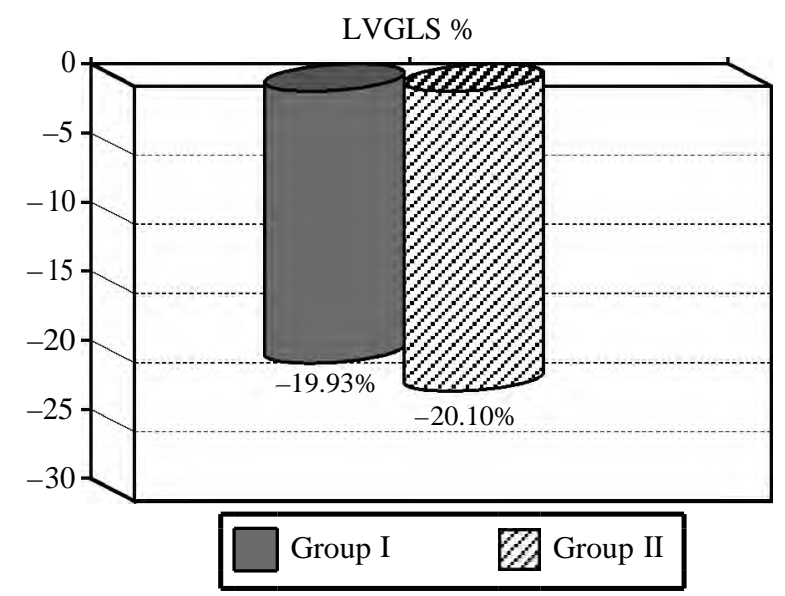

Fig. (1): Bar chart between both groups regarding LVGLS\%.

\section{D STE of the RV:}

A- RVGlobal longitudinal strain (RVGLS \%): Mean values for RVGLS\% showed highly statistically significant difference between both groups, it were lower in group I than group II, as shown in Table (5).

B- Peak longitudinal systolic strain (LSS\%) of RV segments: Mean values for peak LSS\% of RV segments were lower in group I than group II, except for peak LSS\% of Mid RV Free Wall (FW) which showed no statistically significant difference between both groups, as shown in Table (5).

Table (5): Comparison between both groups regarding RVGLS and Peak LSS\% of RV segments.

\begin{tabular}{|c|c|c|c|c|}
\hline 2D STE of RV & Group I & Group II & $t$-test & $p$-value \\
\hline $\begin{array}{l}\cdot R V G L S \%: \\
\text { Mean } \pm \mathrm{SD} \\
\text { Range }\end{array}$ & $\begin{array}{l}-21.49 \pm 3.80 \\
-28-15\end{array}$ & $\begin{array}{l}-26.40 \pm 2.86 \\
-32-22\end{array}$ & 4.677 & $<0.001$ \\
\hline $\begin{array}{c}\text { - Peak LSS\% of } \\
\text { RV segments: }\end{array}$ & & & & \\
\hline $\begin{array}{l}\text { Basal septum: } \\
\text { Mean } \pm \text { SD } \\
\text { Range }\end{array}$ & $\begin{array}{l}-14.81 \pm 4.02 \\
-22-10\end{array}$ & $\begin{array}{l}-21.03 \pm 1.35 \\
-24-18\end{array}$ & 7.908 & $<0.001$ \\
\hline $\begin{array}{l}\text { Mid septum: } \\
\quad \text { Mean } \pm \text { SD } \\
\quad \text { Range }\end{array}$ & $\begin{array}{l}-16.77 \pm 3.66 \\
-25-12\end{array}$ & $\begin{array}{l}-22.73 \pm 2.00 \\
-27-18\end{array}$ & 8.142 & $<0.001$ \\
\hline $\begin{array}{l}\text { Apical septum: } \\
\quad \text { Mean } \pm \mathrm{SD} \\
\text { Range }\end{array}$ & $\begin{array}{l}-18.20 \pm 3.42 \\
-25-11\end{array}$ & $\begin{array}{l}-24.60 \pm 1.94 \\
-29-21\end{array}$ & 10.670 & $<0.001$ \\
\hline $\begin{array}{l}\text { Basal RV FW: } \\
\quad \text { Mean } \pm \mathrm{SD} \\
\quad \text { Range }\end{array}$ & $\begin{array}{l}-20.53 \pm 2.14 \\
-27-16\end{array}$ & $\begin{array}{l}-30.37 \pm 3.11 \\
-38-25\end{array}$ & 38.612 & $<0.001$ \\
\hline $\begin{array}{l}\text { Mid } R V F W: \\
\quad \text { Mean } \pm \text { SD } \\
\quad \text { Range }\end{array}$ & $\begin{array}{l}-29.04 \pm 5.88 \\
-38-21\end{array}$ & $\begin{array}{l}-29.43 \pm 5.16 \\
-39-22\end{array}$ & 0.099 & 0.753 \\
\hline $\begin{array}{l}\text { Apical RV FW: } \\
\quad \text { Mean } \pm \text { SD } \\
\text { Range }\end{array}$ & $\begin{array}{l}-24.41 \pm 5.72 \\
-34-16\end{array}$ & $\begin{array}{l}-30.23 \pm 5.45 \\
-39-21\end{array}$ & 3.194 & 0.006 \\
\hline
\end{tabular}

RVGLS : Right Ventricular Global Longitudinal Strain.

LSS : Longitudinal Systolic Strain.

RV FW : Right Ventricular Free Wall.

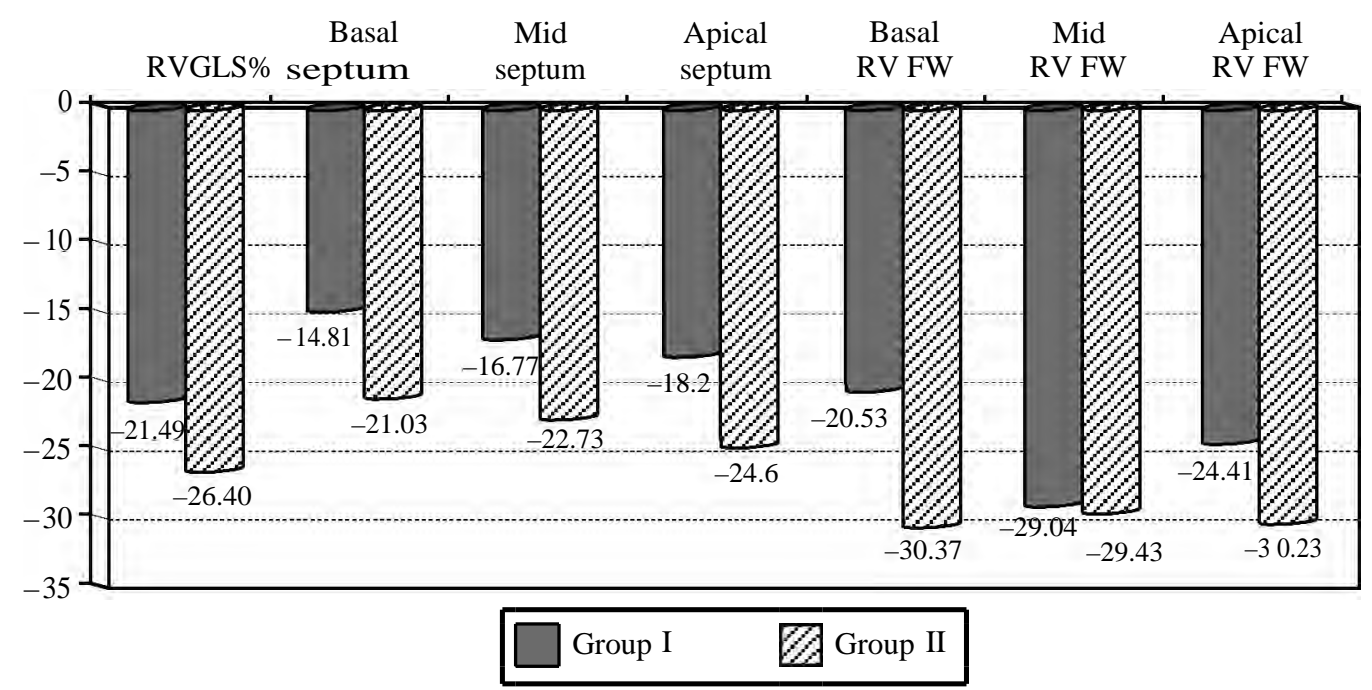

Fig. (2): Bar chart between both groups regarding RVGLS\% and Peak LSS\% of RV segments.

C- Longitudinal Systolic Strain Rates (LSSRs 1/sec) of RV segments: There was no statistically significant difference between both groups regard- ing mean values for LSSRs of RV segments, except for apical RV FWwhich were lower in group I than group II, as shown in Table (6). 
Table (6): Comparison between the two groups regarding LSSRs $(1 / \mathrm{sec})$ of RV segments.

\begin{tabular}{lllll}
\hline $\begin{array}{l}\text { LSSRs }(1 / \mathrm{sec}) \\
\text { of RV segments }\end{array}$ & Patients & Control & $t$-test & $p$-value \\
\hline Basal septum: & & & & \\
$\quad$ Mean \pm SD & $1.15 \pm 0.19$ & $1.13 \pm 0.19$ & 0.322 & 0.572 \\
Range & $0.88-1.61$ & $0.88-1.5$ & & \\
& & & & \\
Mid septum: & & & & \\
Mean \pm SD & $1.15 \pm 0.17$ & $1.16 \pm 0.18$ & 0.032 & 0.859 \\
Range & $0.88-1.55$ & $0.88-1.55$ & & \\
Apical septum: & & & & \\
Mean \pm SD & $1.06 \pm 0.14$ & $1.06 \pm 0.14$ & 0.052 & 0.821 \\
Range & $0.85-1.35$ & $0.85-1.35$ & & \\
Basal $R V F W:$ & & & & \\
$\quad$ Mean \pm SD & $2.66 \pm 0.95$ & $2.72 \pm 0.96$ & 0.082 & 0.775 \\
Range & $0.96-4.52$ & $0.96-4.52$ & & \\
Mid $R V F W:$ & & & & \\
Mean \pm SD & $2.97 \pm 1.39$ & $2.97 \pm 1.31$ & 0.000 & 0.990 \\
Range & $0.89-5.91$ & $0.89-5.13$ & & \\
Apical $R V F W:$ & & & & \\
$\quad$ Mean $\pm \mathrm{SD}$ & $1.18 \pm 0.54$ & $1.48 \pm 0.54$ & 4.124 & 0.022 \\
Range & $0.48-2.45$ & $0.88-2.45$ & & \\
\hline
\end{tabular}

LSSRs : Longitudinal Systolic Strain Rates.

RV FW : Right Ventricular Free Wall.

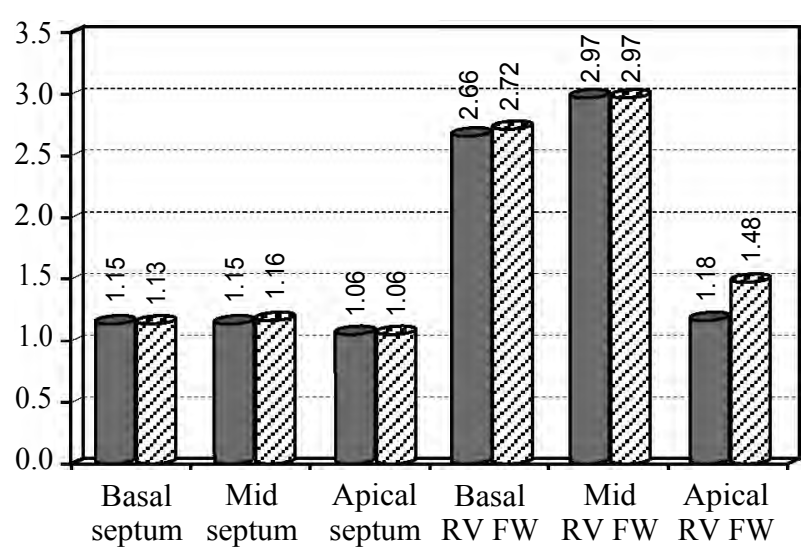

$$
\text { Group I } Q 2 \text { Group II }
$$

Fig. (3): Bar chart between both groups regarding LSSRs $(1 / \mathrm{sec})$ of RV segments.

\section{$L V G L S \%$ and $D M$ :}

1- The higher the level of $\mathrm{HbA} 1 \mathrm{c} \%$, the lower the value of $\mathrm{LVGLS} \%$, as there was a reverse correlation between LVGLS\% and HbA1c level, coefficient $(r)=0.911$. $p$-value $<0.001$, as shown in Fig. (4).

2- The longer the duration of DM, the lower the value of LVGLS\%, as there was a reverse correlation between LVGLS\% and duration of DM, coefficient $(r)=0.866$. $p$-value $<0.001$, as shown in Fig. (5).

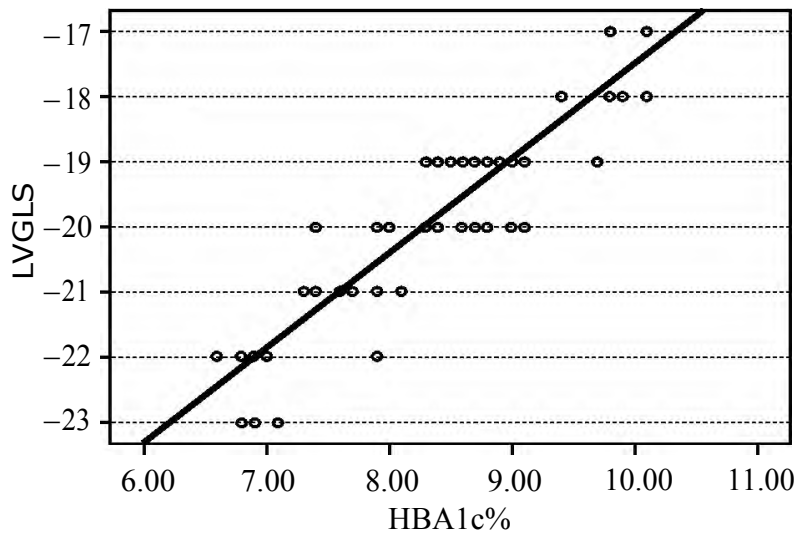

Fig. (4): Scatter plot showing a reverse correlation between LVGLS\% and HBA $1 \mathrm{c} \%$ level.

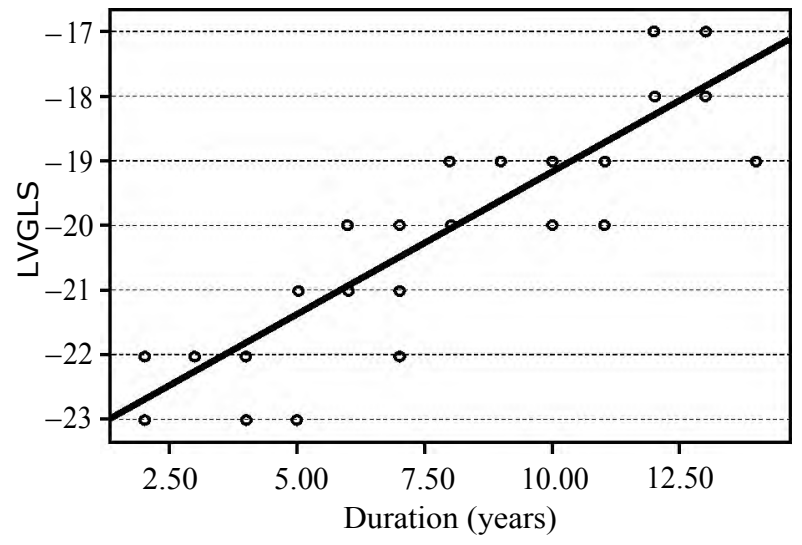

Fig. (5): Scatter plot showing a reverse correlation between LVGLS\% and the duration of diabetes.

\section{$R V G L S \%$ and DM:}

1- The higher the level of $\mathrm{HbA} 1 \mathrm{c} \%$, the lower the value of RVGLS\%, as there was a reverse correlation between RVGLS\% and HbA1c level, coefficient $(r)=0.927$. $p$-value $<0.001$, as shown in Fig. (6).

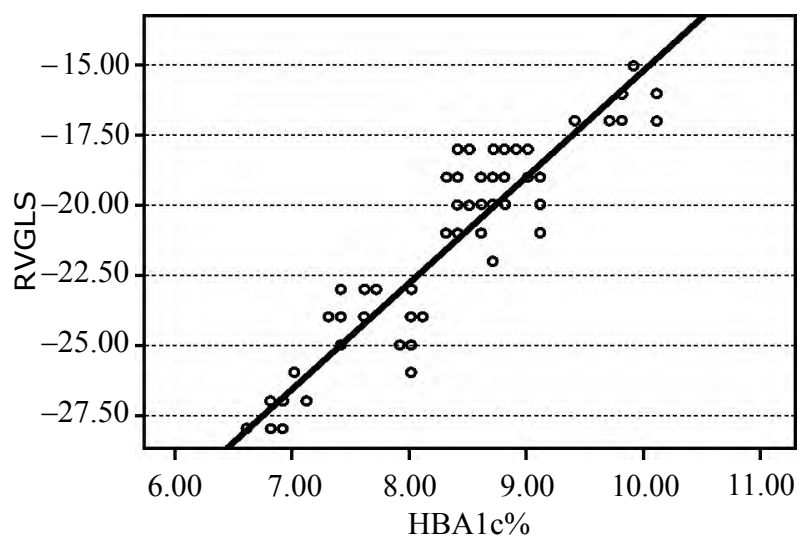

Fig. (6): Scatter plot showing a reverse correlation between reduction of RVGLS and HBA1c\% level.

2- The longer the duration of DM, the lower the value of RVGLS\%, as there was a reverse cor- 
relation between RVGLS\% and duration of DM, coefficient $(r)=0.918$. $p$-value $<0.001$, as shown in Fig. (7).

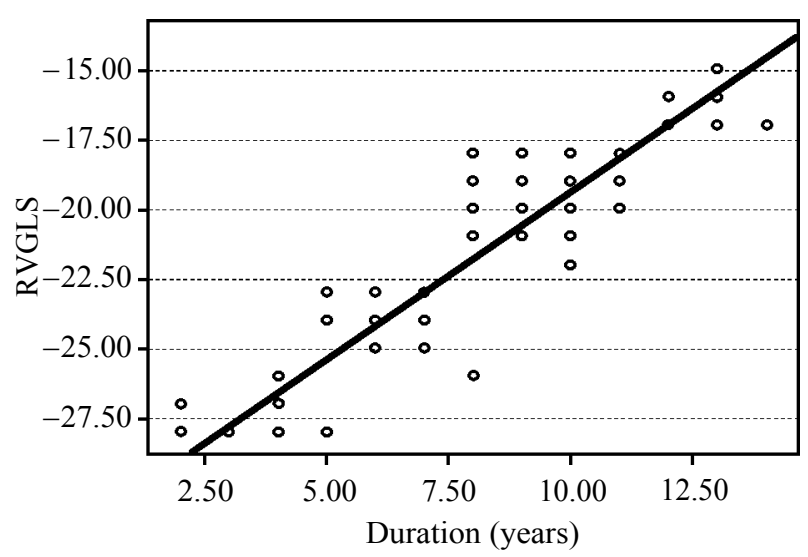

Fig. (7): Scatter plot showing a reverse correlation between RVGLS\% and the duration of diabetes.

\section{Discussion}

The study aimed to assess the RV systolic function in asymptomatic normotensive subjects with type II diabetes mellitus compared with control subjects, using strain/strain rate qualification by 2D STE.

The study included 70 subjects ( 36 males and 34 females) known to have type II diabetes mellitus and 30 apparently normal people with matched age, sex status as controls ( 15 males and 15 females).

Both groups showed no statistically significant difference regarding LVEDD, LVESD, EF, LVMI, $\mathrm{RV}$ inflow linear dimensions, TAPSE and FAC.

The current study found that the mean values of LVGLS\% were significantly lower in group I than in group II, which may indicate subclinical impairment of LV systolic function ( $p$-value $<0.001)$.

These findings are concordant with the following reports:

1-Nakai et al., [10], who evaluated subclinical LV dysfunction in asymptomatic diabetic patients assessed by 2D STE in correlation with diabetic duration, in their study 60 asymptomatic diabetic patients with normal LVEF and 25 age-matched healthy volunteers. Using 2D strain software, endsystolic LS, was measuredin $18 \mathrm{LV}$ segments.

2- Mochizuki et al., [11], who evaluated subclinical LV systolic dysfunction in patients with DM assessed by 2D STE, in their study 144 asymp- tomatic type II DM patients without coronary artery disease, with preserved LVEF (mean LVEF was $66 \pm 4 \%$ (all $\geq 50 \%$ ). With the pre-defined cutoff for subclinical LV systolic dysfunction in DM patients with preserved LVEF set at GLS $<18 \%$, this dysfunction was detected in 53 patients (37\%).

3- Karagöz et al., [12], who evaluated subclinical LV systolic dysfunction in 82 type II DM patients and 90 gender-matched healthy controlsassessed by 2D STE. All diabetic patients had preserved LV Ejection Fraction (LV-EF $\geq 50$ ). The study group was observed to havestatistically significant lower peak LS values compared with the control group. ( $p$-value $<0.001)$. Moreover, LV global strain values were found to be significantly lower in the DM group than in the control group, ( $p$-value $<0.001)$.

4- Enomoto et al., [13], who evaluated subendocardial systolic dysfunction in asymptomatic normotensive diabetic patientsassessed by 2D STE. In their study, 104 patients with poorly controlled type $2 \mathrm{DM}$ (mean HbA1c level, 10\%) and 24 ageand sex-matched healthy volunteers, patients with coronary artery stenosis or structural heart disease were excluded. Compared with the healthy control group, the normotensive diabetes group showed no significant difference in ejection fraction, left ventricular mass index, diastolic properties, left atrial volume index, or B-type Natriuretic Protein (BNP) level, but LVGLS was significantly deteriorated in diabetic patients.

The present study found that the mean values of RVGLS\% were significantly lower in group I than in group II, which may indicate subclinical impairment of RV systolic function ( $p$-value $<0.001)$.

These findings are concordant with the following reports:

1- Kosmala et al., [14] . Subclinical RV dysfunction in DM was assessed using strain/strain rate in 33 subjects with diabetes; aged $57.3 \pm 12.9$ years and 40 subjects with coexisting DM and hypertension; aged $57.5 \pm 10.5$ years. In all patients with diabetes, coronary artery disease and pulmonary hypertension were excluded. 36 healthy age matched persons served as control subjects. They found significantly lower values of LSS of the RV free wall in the DM and DM and HTN groups as compared with control subjects indicated impairment of RV systolic function.

2- Tadic et al., [15], who evaluated the influence of type $2 \mathrm{DM}$ and arterial hypertension on RV layer-specific mechanics by using 2D STE. In their study, 129 subjects ( 40 controls, 42 normotensive 
DM and 47 hypertensive DM patients) underwent complete 2D TTE including multilayerstrain analysis. Subjects with symptoms or signs of cardiovascular diseases (heart failure, myocardial infarction, significant valve disease, atrial fibrillation, congenital heart disease), obesity (BMI > $30 \mathrm{~kg} / \mathrm{m}^{2}$ ), neoplastic disease, cirrhosis of the liver or kidney failure were excluded from the study. RVGLS and segmental LSS values of RV FW were reduced in normotensive and hypertensive DM subjects than in controls, RV global longitudinal layer-specific strains (endo, mid, and epicardial) were lower in normotensive and hypertensive DM patients than in controls.

In the present study, RV segmental peak LSS\% showed statistically significant difference between both groups, as the mean values for peak LSS\% of RV segments were lower in group I than in group II ( $p$-value $<0.001)$, except for the peak LSS\% of mid RV FW, which showed no statistically significant difference between both groups.

Also, RV segmental LSSRs (1/sec) of showed no statistically significant difference between both groups, except the mean values for LSSRs of apical RV FW, which were significantly lower in group I than in group II ( $p$-value $=0.022)$.

These findings of the present study are concordant with the following reports:

1-Parsaee et al., [16], who evaluated subclinical $\mathrm{RV}$ dysfunction in type II DM patients assessed by strain and strain rate study. In their study, 22 diabetic patients without any coronary artery disease, hypertension, or LV dysfunction were studied. The RV end diastolic diameter, TAPSE, RV inflow, Doppler parameters, longitudinal myocardial velocities, and deformation indices from the basal and apical segments of the RV FW ofthe case group were measured. The control group consisted of 22 healthy individuals. Basal and apical RV FW systolic strain $(-13.3 \%$ and $-18.7 \%$ vs. $-20.2 \%$ and $-25.7 \% ; p$-value $=0.001)$, and apical strain rate $(-1.21 / \mathrm{s}$ vs. $-1.61 / \mathrm{s} ; p$-value $=0.008)$ were significantly lower in the study group. There were, however, no significant differences in regard to the RV basal segment strain rate between the two groups.

2- Kosmala et al., [14], who reported the impairment of both basal and apical segments of the RV FW performance. The apical segments exhibited more pronounced systolic impairment than did the basal segments.

The explanation of these findings is related to the difference between the three parts of RV (inflow, trabecular portion and outflow), the inflow region, compared with the other parts of the RV, had significant predominance in fiber shortening and contribution to the global RV systolic function. As the basal segment of the RV FW is a part of the inflow component, and the apical segment refers to the trabecular portion of the RV, they suggested that the differences seen in their cohort might be related to the regional inhomogeneity of the $\mathrm{RV}$ in patients with DM [17]

In the present study, there was a reverse correlation between LVGLS and RVGLS with the duration of DM in group I ( $p$-value $<0.001)$.

This finding is concordant with the following reports:

1- Nakai et al., [10], who evaluated subclinical LV dysfunction in asymptomatic DM patients assessed by 2D STE in correlation with diabetic duration, they found that diabetic duration was the only independent confounder for the reduction of GLS.

2- Elgohary et al., [18]. In their study, 52 diabetic patients had been tested for HbA $1 \mathrm{c}$ test and stratified into two groups. Group I it included 26 DM patients ( $<$ or $>$ five years) with controlled blood sugar. Group II: It included 26 DM patients (< or $>$ five years) with uncontrolled blood sugar. Patients with IHD, systolic dysfunction, CHD, valvular diseases, arrhythmias, HOCM, Pericardial, major systemic disease had been excluded. There was significant statistical difference in GLS, age, diabetic type, diabetic duration in controlled DM compared to uncontrolled DM ( $p>0.05$ years), significant statistical difference in GLSin $(<5$ years to $>5$ years) diabetic duration $(p<0.05)$. So, diabetic duration was strongly correlated with reduction of (GLS).

However the finding isdiscordant with the following reports:

1- Parsaee et al., [16], they found a weak correlation between the RVGLS\% and HbA1c as well as the duration of diabetes mellitus and C-reactive protein. This could be explained by the glycaemic control of the whole diabetes duration was relatively good and this might partially explain the lack of the relationship of the diabetic duration and the reduction of RVGLS.

2- Kosmala et al., [14] and Elshahed et al., [19], those found no importance for the impact of the duration of diabetes on the $\mathrm{RV}$ function. Both studies used TDI for calculation of strain and strain rates. 
In the present study, there was a reverse correlation between LVGLS and RVGLS with the level of HbA1c in group I ( $p$-value $<0.001)$.

This finding is concordant with Leung et al., [20], who evaluated impact of improved glycaemic control on cardiac function in 105 patients with type $2 \mathrm{DM}$ patients assessed by 2D STE. In their study, a total of 105 subjects with type 2 DM (aged $54 \pm 10$ years) and poor glycaemic control. Patients were received optimization of treatment for blood glucose, blood pressure, and cholesterol to recommended targets for 12 months. LV systolic and diastolic function, measured by LVGLS and septal é velocities, were compared before and after optimization. At baseline, patients had impaired LV systolic (GLS $-14.9 \pm 3.2 \%$ ) and diastolic function (é $6.2 \pm 1.7 \mathrm{~cm} / \mathrm{s}$ ). After 12 months, glycated hemoglobin $(\mathrm{HbA} 1 \mathrm{c})$ decreased from $10.3 \pm 2.4 \%$ to $8.3 \pm 2.0 \%$, which was associated with significant relative improvement in GLS of $21 \%$ and septal é of $24 \%$. There was a progressively greater improvement in GLS as patients achieved a lower final $\mathrm{HbA1c}$. Patients achieving an HbA1c of $<7.0 \%$ had the largest improvement. The 15 patients whose $\mathrm{HbA1c}$ worsened experienced a decline in GLS. Patients whoimproved their HbA1c by $\geq 1.0 \%$ had a significantly higher relative improvement in é than those who did not ( $32 \%$ versus $8 \% ; p=0.003$ ).

But this correlation is discordant with the following reports:

1-Jedrzejewska et al., [21], their study evaluated LV \& RV systolic function impairment in type I diabetic young adults assessed by 2D STE. In their study 50 patients with type $1 \mathrm{DM}$ and 50 control subjects in the same range of age were prospectively evaluated, they did not find any relationship between systolic or diastolic parameters and $\mathrm{HbA1c}$.

2- Di Cori et al., [22], who did not observe any correlation between $\mathrm{HbA} 1 \mathrm{c}$ and LVGLS or diastolic parameters in forty asymptomatic and uncomplicated patients with type $1 \mathrm{DM}$ and this could be explained that from the baseline characteristics of patients that were more strictly selected and more likely to represent a very early preclinical stage of the disease and good glycaemic control of them.

3- Kim and Kim [23], who did not find a relationship between $\mathrm{HbA1c}$ and LV systolic strain or velocity.

The lack of correlation between HbA1c and myocardial function may be explained by the fact that $\mathrm{HbA} 1 \mathrm{c}$ reflects the glucose level of only 4 preceding months. As an indicator of short term hyperglycemia, it cannot show the relationship of glycaemic control with cardiac function in long disease duration diabetic patients. Another explanation may be hyperglycaemic memory, in this phenomenon, endothelial dysfunction induced by hyperglycaemic stress is present even after glucose normalization. This means that diabetic vascular complications progress despite the restoration of normal glucose level [24].

\section{Conclusion: The study concluded that:}

- Subjects with type II DM were associated with subclinical LV \& RV systolic dysfunction compared with control subjects.

- The 2D STE technique may be superior than conventional 2D TTE for early detection of subclinical LV \& RV systolic dysfunction in asymptomatic subjects with type II DM.

- This study suggested that the main risk factors for impairment of LVGLS \& RVGLS in patients with type II DM are glycaemic control and the duration of diabetes.

\section{Recommendations:}

The study recommended that:

- Serial echocardiographic assessments are indicated in a symptomatic patient with type II DM for early detection of subclinical ventricular dysfunction before the development of symptomatic ventricular dysfunction.

- The STE technique should be combined with conventional echocardiography for follow-up of ventricular function in diabetic patients.

- Routine testing of blood glucose level should be done, control diet ,avoiding heavy meals, stop smoking and avoiding other risk factors of diabetes. Therefore, alteration of myocardial function induced by DM may begin earlier than is generally thought and these changes may be accelerated when glycemic control is poor.

- Extension of the study in a large scale of patients is good for validation of our observation.

\section{Study limitations:}

- This study is limited by the relatively small sample size.

- The accuracy of STE largely depends on image quality; however, many patients were excluded from our study because of inadequate image quality.

- Radial and circumferential strains were not performed. 
- The software of LVSTEwas used to assess the $\mathrm{RV}$ because there is no available software for RV STE.

- No follow-up was done for these patients to detect the occurrence of clinical diabetic cardiomyopathy.

- HbA1c was tested only once at the day of echocardiographic examination. Therefore, glycaemic control of the whole diabetic duration in our patients was unknown.

\section{References}

1- VOULGARI C., PAPADOGIANNIS D. and TENTOLOURIS N.: Diabetic cardiomyopathy from the pathophysiology of the cardiac myocytes to current diagnosis and management strategies. Health Risk Manag., 6: 883-903, 2010.

2- MIKI T., YUDA S., KOUZU H., et al.: Diabetic cardiomyopathy pathophysiology and clinical features. Heart Fail Rev., 18: 149-66, 2013.

3- BUGGER H. and ABEL E.D.: Molecular mechanisms of diabetic cardiomyopathy. Diabetologia, 57: 660-77, 2014.

4- POORNIMA I.G., PARIKH P. and SHANNON R.P.: Diabetic cardiomyopathy the search for a uni-fying hypothesis. Circ. Res., 98: 596-605, 2006.

5- ERNANDE L., RIETZSCHEL E.R., BERGEROT C., et al.: Impaired myocardial radial function in asymptomatic patients with type 2 diabetes mellitus: A speckletracking imaging study. J. Am. S. Echocardiogr., 23: 1266-72, 2010.

6- VAN DEN BROM C.E., BOSMANS J.W., VLASBLOM R., HANDOKO L.M., HUISMAN M.C., LUBBERINK M., MOLTHOFF C.F., LAMMERTSMA A.A., OUWENS M.D., DIAMANT M. and BOER C.: Diabetic cardiomyopathy in Zucker diabetic fatty rats: The forgotten right ventricle. J. Cardiovasc. Diabetologia., 9: 25-32, 2010.

7- Di SALVO G., DRAGO M., PACILEO G., CARROZZA M., SANTORO G., BIGAZZI M.C., et al.: Comparison of strain rate imaging for quantitative evaluation of regional left and right ventricular function after surgical versuspercutaneous closure of atrial septal defect. Am. J. Cardiol., 96: 299-302, 2005.

8- MOR-AVI V., LANG R.M., BADANO L.P., et al.: Current and evolving echocardiographic techniques for the quantitative evaluation of cardiac mechanics: ASE/EAE consensus statement on methodology and indications endorsed by the Japanese Society of Echocardiography. Eur. J. Echocardiogr., 12: 167-205, 2011.

9- LURBE E., CIFKOVA R., CRUICKSHANK J.K., et al.: Management of high blood pressure in children and adolescents: Recommendations of the European Society of Hypertension. J. Hypertens, 27: 1719-42, 2009.

10- NAKAI H., TAKEUCHI M., NISHIKAGE T., et al.: Subclinical left ventricular dysfunction in asymptomatic diabetic patients assessed by two-dimensional speckle tracking echocardiography: Correlation with diabetic duration. European Journal of Echocardiography, 10: 92632, 2009.

11-MOCHIZUKI Y., TANAKA H., MATSUMOTO K., SANO H., TOKI H., SHIMOURA H., OOKA J., SAWA T., MOTOJI Y., RYO K., HIROTA Y., OGAWA W. and HIRATA K.: Clinical features of subclinical left ventricular systolic dysfunction in patients with diabetes mellitus. Mochizuki et al.; licensee Bio. Med. Central, 2015.

12-KARAGÖZ A., BEZGIN T., KUTLUTÜRK I., KÜLAHÇıOGLU S., TANBO GA I.H., GÜLER A., KARABAY C.Y., ODUNCU V., AKSOY H. and KiRMA C.: Subclinical left ventricular systolic dysfunction in diabetic patients and its association with retinopathy, A 2D Speckle tracking echocardiography study. Herz, (Suppl 3): 40: 240-6, 2015.

13- ENOMOTO M., M.D.; ISHIZU T., M.D., Ph.D.; SEO Y., M.D., Ph.D.; YAMAMOTO M., M.D.; SUZUKI H., M.D., Ph.D.; SHIMANO H., M.D., Ph.D.; KAWAKAMI Y., M.D., Ph.D. and AONUMA K., M.D., Ph.D.: Subendocardial Systolic Dysfunction in Asymptomatic Normotensive Diabetic Patients (Circ. J., 79: 1749-55), 2015.

14- KOSMALA W., PRZEWLOCKA-KOSMALA M. and MAZUREK W.: Subclinical right ventricular dysfunction in diabetes mellitus-an ultrasonic strain/strain rate study. Diabet. Med. Jun., 24 (6): 656-63, 2007.

15- TADIC M., CUSPIDI C., VUKOMANOVIC V., ILIC S., CELIC V., OBERT P. and KOCIJANCIC V.: The influence of type 2 diabetes and arterial hypertension on right ventricular layer-specific mechanics, 2016.

16- PARSAEE M., M.D., BAHMANZIARI P., M.D., ARDESHIRI M., M.D., and ESMAEILZADEH M., M.D.: Obvious or Subclinical Right Ventricular Dysfunction in Diabetes Mellitus (Type II): An Echocardiographic Tissue Deformation Study J. Tehran Heart Cent., Nov., 7 (4): 177-81, 2012.

17- GEVA T., POWELL A.J., CRAWFORD E.C., CHUNG T. and COLAN S.D.: Evaluation of regional differences in right ventricular systolic function by acoustic quantification by echocardiography and cine magnetic resonance imaging. Circulation, 98: 339-45, 1998.

18- ELGOHARY A., SHALABY M., MAHFOUZ R. and MOHAMED M.: Effect of diabetic duration on left ventricular global longitudinal strain by speckle tracking imaging. The American Journal of Cardiology, March 2326, 2017. International Congress of Update in Cardiology and Cardiovascular Surgery Abstracts/Oral, 2017.

19- ELSHAHED G.S., AHMED M.I., EL-BEBLAWY N.S., KAMAL H.M., LSMAIL M.F. and BIN ZHEIDAN O.A.S.: Evaluation of right and left ventricular systolic and diastolic function in patients with type I diabetes using echocardiography and tissue Doppler imaging. Suez Canal Univ. Med. J., 11: 65-74, 2008.

20- LEUNG M., M.B.B.S., B.Sc. (Med.), MBIOSTAT, Ph.D.; VINCENT W. WONG, M.B.B.S., Ph.D.; HUDSON M., B.Sc., Ph.D. and DOMINIC Y. LEUNG, M.B.B.S., Ph.D.: Impact of Improved Glycemic Control on Cardiac Function in Type 2 Diabetes Mellitus (Circ. Cardiovasc. Imaging; 9: e003643), 2016.

21- JEDRZEJEWSKA I., KROL W., SWIATOWIEC A., et al.: Left and right ventricular systolic function impairment 
in type 1 diabetic young adults assessed by $2 \mathrm{D}$ speckle tracking echocardiography. Eur. J. Echocardiogr., 4: 43846, 2016.

22- Di COЮ A., Di BELLO V., MICCOLI R., et al.: Left ventricular function in normotensive young adults with well-controlled type I diabetes mellitus. Am. J. Cardiol., 99: 84-90, 2007.
23- KIM E.H. and KIM Y.H.: Left ventricular function in children and adolescents with type I diabetes mellitus. Korean Circ. J., 40: 125-30, 2010.

24- PANENI F., MOCHARLA P., AKHMEDOV A., et al.: Gene silencing of the mitochondrial adaptor p66 (Shc) suppresses vascular hyperglycemic memory in diabetes. Circ. Res., 111: 278-89, 2012.

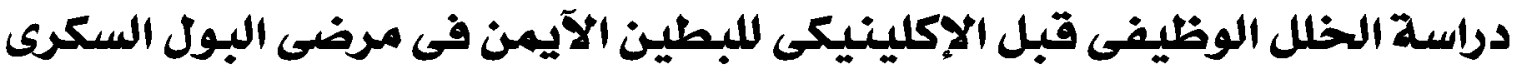

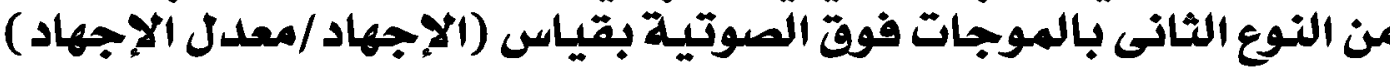

قد يؤدى مرض السكرى إلى إعتلال وظيفة عضلة القلب بالرغم من عدم وجود مرض الشريان التاجى وإرتفاع ضغط الدام ويكون تمدد عضلة

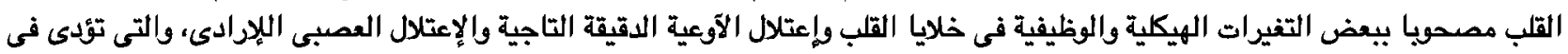

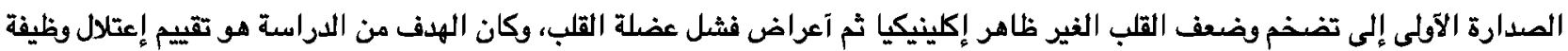

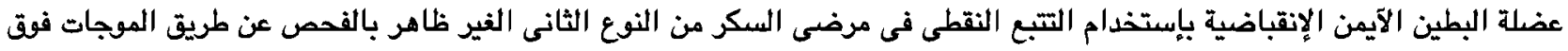

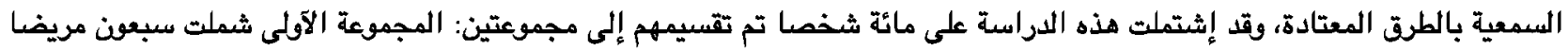

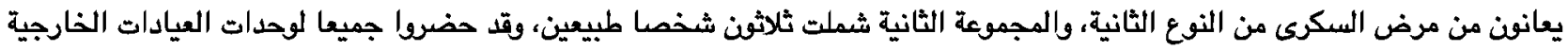

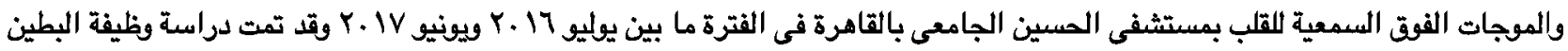

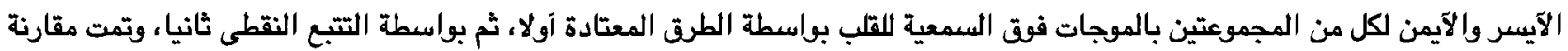

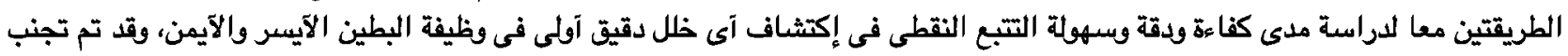

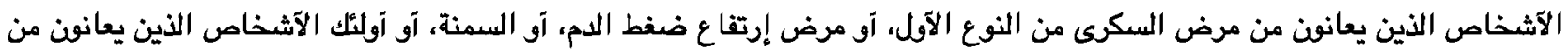

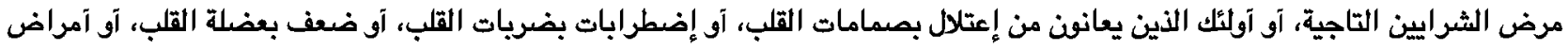

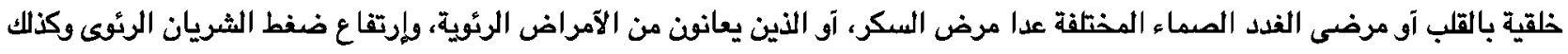

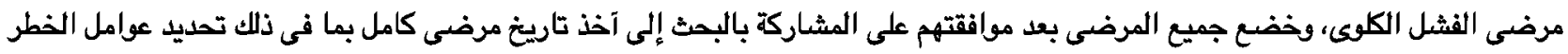

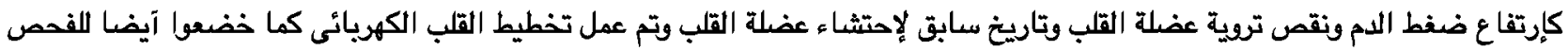

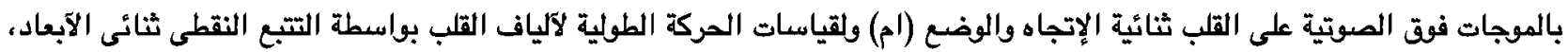

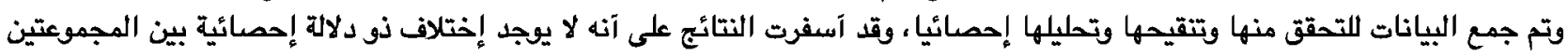

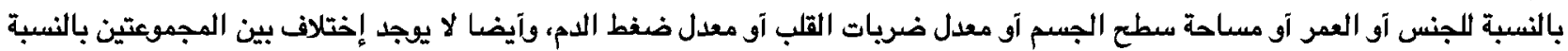

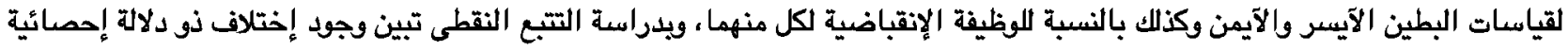

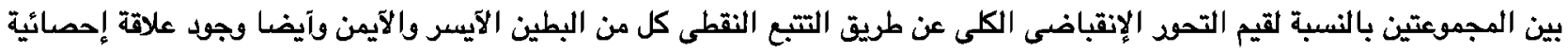

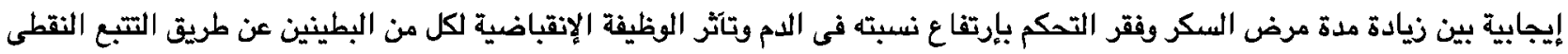

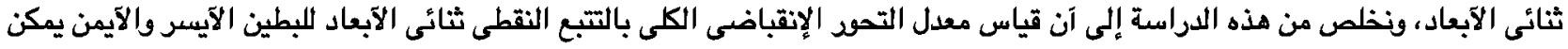

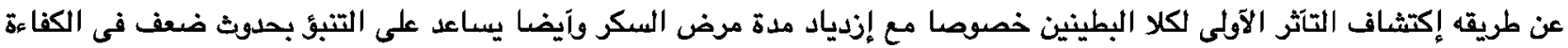

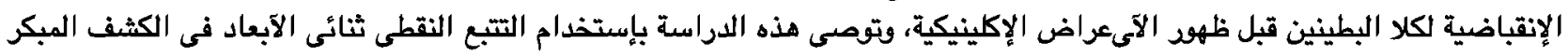
عن ضعف عضلة القلب الغير ظاهر إكلينيكيا الناجم عن مرض الإنيك السكر. 